\title{
Improved control algorithm for shunt reactors using fuzzy logic
}

\author{
Etibar Pirverdiyev ${ }^{l}$, Arif Hashimov², Aytek Babayeva $^{2}$, Huseynqulu Guliyev $^{2 *}$ \\ ${ }^{1}$ Azerenerji OJSC, AZ 1005, A.Alizade str.,10, Azerbaijan \\ ${ }^{2}$ Azerbaijan Scientific-Research and Designed-Prospecting Institute of Power Engineering, AZ1012, Zardabi ave, 94, \\ Azerbaijan
}

\begin{abstract}
The task of provision of the efficiency of fuzzy controller action, regulating the power of shunt reactors, is considered for the stabilization of the voltage values in high-voltage buses, as well as to increase the regime reliability of the power grid. A new algorithm is proposed for controlling the power or inductive resistance of reactor depending on the load resistance, rate of change and voltage on the network buses. The results of the designed experiment based on computer simulation confirm the effectiveness of the proposed control algorithm.
\end{abstract}

\section{Introduction}

In extended high-voltage power lines $(110-500 \mathrm{kV})$ and cable systems a shunt reactor (SR) is widely used to compensate for reactive power (charging power). Use of SR allows for solving such problems as unloading of power grid from the charging power in order to reduce losses, smooth and fast control of reactive power, damping of oscillations of active power and voltage on high-voltage buses, in general, the implementation of the tasks of improving the static and dynamic stability of the power system.

SR can be directly connected to the power transmission lines, buses, three-phase transformer (autotransformer) permanently or by means of automatic switch [1,2]. To improve the control of the required reactive power, the reactor must have adjustable parameters.

If the load changes gradually (seasonally, daily or hourly), the use of controlled shunt reactor (CSR) may be one of the best problem solutions. At the same time, in the conditions of short-term and relatively long-term sharp fluctuations of the transmitted power and, accordingly, the load of the high-voltage power grid, the need for effective control of the SR, i.e. the optimal control of the required reactive power is created. In uncertain initial information conditions, the SR control management is subject to a number of difficulties. Under these conditions, the existing SR control systems cannot form a rational control action due to the problems of fluctuations and sharp deviations of voltage on highvoltage buses, as well as the occurrence of overvoltages associated with the implementation of frequent unreasonable switchovers $[3,4]$.

One of the options for the problem is the use of the transformer type SR produced by foreign (for example,
ABB) firms with a thyristor control system, which has a core with an air gap filled with oil. As the studies show, when setting the controlled parameters in the conditions of real initial information data, the use of the SR with the control system implementing a particular traditional algorithm does not fully provide the desired results [5, $6]$.

In this regard, under the above conditions, the creation of the algorithm and control system for SR on the basis of the theory of fuzzy sets and fuzzy logic proposed by the famous Professor L. Zadeh is topical and of scientific interest [6]. The authors of this paper proposed such a system [7]. In this system the primary input parameters are the load resistance $Z$ and its rate of change $d Z / d t$, and the controlled output parameter is the reactive power of the CSR. Despite the effectiveness of the CSR operation on the basis of the proposed fuzzy logic controller, the intellectualization of the facility is not fully provided, and in some cases there is a problem with the stabilization of the voltage on the high-voltage buses of the power grid. To eliminate these shortcomings, the task of improving and developing of the proposed control algorithm for the fuzzy logic controller (FLC) is assigned. For this purpose, the input and output vectors of linguistic variables are increased by one order, i.e. the current values of bus voltage were added to the input of the FLC, to which the CSR is connected, and to the output - the delay time of the control system action depending on the nature of the load resistance change (Fig.1). 


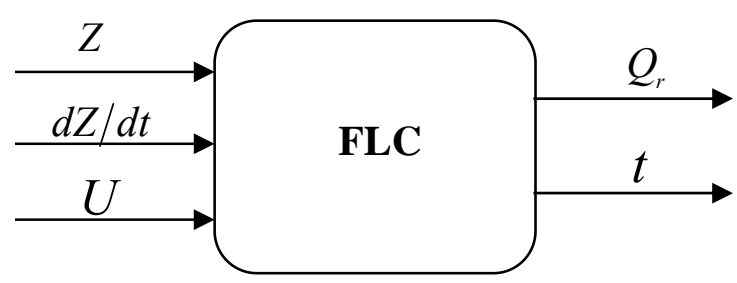

Fig.1. Fuzzy logic controller for CSR

Thus, the synthesized new type of FLC has a control system with three input and two output linguistic parameters, which allows for effective control of the output reactive powers of the CSR installed at the beginning and at the end of power transmission line of the power grid. In this paper, the synthesis and implementation of the FLC with three input and two output parameters for the CSR output power control in the initial fuzzy-probabilistic information environment are considered.

\section{Fuzzy control algorithm for CSR}

It is known that the dependence of the reactive power $Q_{r}$ required by the CSR on the line parameters is expressed by the formula $[2,3]$ :

$$
Q_{r}=P_{n a t} \cdot \lambda \cdot\left[1-\left(\frac{P}{P_{n a t}}\right)^{2}\right] \cdot L
$$

where $P$ - active power transmitted over power line; $P_{n a t}$ - natural power of power line; $L-$ length of power line; $\lambda$ - wave length.

When controlling a reactor with a traditional control system, realizing the control algorithm worked-out based on the formula (1), it is impossible to effectively regulate the reactive power of the CSR due to the above reasons. The proposed FLC realizes the $\widetilde{Q}_{r}=f(Z, d Z / d t)$ algorithm.

As mentioned above, this control algorithm cannot fully provide a voltage stabilization on the buses. For this purpose, one more parameter was added in the input - the bus voltage, and one more parameter in the output the FLC action delay time, which is set depending on the load resistance change rate. The proposed FLC realizes two laws of fuzzy control:

$$
\left\{\begin{array}{l}
\widetilde{Q}_{r}=f(U, Z, d Z / d t) \\
t=f(U, Z, d Z / d t)
\end{array}\right.
$$

It is known that any FLC consists of fuzzificator, fuzzy logic output mechanism and defuzzificator, and depending on the task, it realizes the appropriate algorithm [3-6].

In this case, the fuzzy control algorithm (2) should be worked-out based on a fuzzy model of linguistic approximation with three input and two output parameters:

$$
\text { if } X_{1}=A_{1} \text { and } X_{2}=A_{2} \text { and } X_{3}=A_{3} \text { then } Y_{1}=B_{1} \text { and } Y_{2}=B_{2}
$$

where $X_{1}, X_{2}, X_{3}$ - input linguistic variables of the controlled objects; $A_{1}, A_{2}, A_{3}$ - fuzzy subsets defined in the universal sets $E_{1}, E_{2}, E_{3}$, respectively, consisting of terms of linguistic variables $X_{1}, X_{2}, X_{3} ; Y_{1}, Y_{2}$ - output linguistic variables of the controlled objects; $B_{1}, B_{2}-$ fuzzy subsets defined in the universal sets $E_{4}, E_{5}$, respectively, consisting of terms $Y_{1}, Y_{2}$, where $\forall x_{i} \quad A_{i} \in E_{i}, i=1 \ldots 3$ и $\forall y_{j} \quad B \in E_{j}, j=1,2$.

For input linguistic variables $X_{1}, X_{2}, X_{3}$, the membership functions of Gaussian (qaussmf), for output variables $-Z$ - shaped (zmf), $S$ - shaped (smf) and trapezoidal (trapmf) membership functions are adopted $[6,8]$ :

qaussmf function:

$$
\mu_{k i}(x)=\exp \left(\frac{-\left(x_{i}-m_{k i}\right)}{2 \sigma_{k i}^{2}}\right), \quad i=\overline{1, n} \quad k=\overline{1, m}
$$

trapmf function:

$$
\mu_{k i}(x)= \begin{cases}0, & x_{i} \leq a_{k i} \\ \frac{x_{i}-a_{k i}}{b_{k i}-a_{k i}}, & a_{k i} \leq x_{i} \leq b_{k i} \\ 1, & b_{k i} \leq x_{i} \leq c_{k i} \\ \frac{d_{k i}-x_{i}}{d_{k i}-c_{k i}}, & c_{k i} \leq x_{i} \leq d_{k i} \\ 0, & d_{k i} \leq x_{i}\end{cases}
$$

$\mathrm{zmf}$ and smf functions

$\mu_{k i}(x)=\left\{\begin{array}{lc}1, & x_{i} \leq a_{k i} \\ \text { nonlinearapproximation, }, & a_{k i}<x_{i}<b_{k i} \\ 0, & x_{i} \geq b_{k i}\end{array}\right.$

where $m$ - coordinate of the maximum; $\sigma$ concentration factor; $a, d$ - fuzzy set carrier; $b, c$ fuzzy set kernel, $\mu_{A, i}(x): X_{i} \rightarrow[0,1]$.

After determining the fuzzy implication and the type of membership function on the basis of fuzzy approximation between the input and output vectors, the output signals are formed. 


\section{Determination of parameters of membership function and drawing up of the control algorithm}

$$
\begin{aligned}
& E_{41}=\operatorname{Max} \quad(\text { maximum }) \quad \triangleq\left(Q_{p}, \mu_{41}\left(Q_{r}\right)\right) \\
& E_{42}=B \quad(\mathrm{big}) \quad \triangleq\left(Q_{p}, \mu_{42}\left(Q_{r}\right)\right) \\
& E_{43}=M \quad \text { (mean) } \quad \Delta\left(Q_{p}, \mu_{43}\left(Q_{r}\right)\right) \\
& E_{44}=S \quad \text { (small) } \quad \triangleq\left(Q_{p}, \mu_{44}\left(Q_{r}\right)\right) \\
& E_{45}=Z R \quad \text { (zero) } \quad \triangleq\left(Q_{p}, \mu_{45}\left(Q_{r}\right)\right)
\end{aligned}
$$

Mamdani algorithm was used in the preparation of the fuzzy logic controller (FLC) algorithm. When programming according to the Mamdani algorithm ("reactive power consumption of the reactor - line load" relationship) for the input (voltage, load resistance and its rate of change) and output (delay time and reactive power of the reactor) parameters, the following fuzzy term-subsets are accepted:

- Term-set $T_{i}(Z)$ for the linguistic variable "Load resistance", where $Z_{i} \in E_{1 i}$ with $i=\overline{1,5}$ :

$$
\begin{array}{lcl}
E_{11}=V B & \text { (very big) } & \underline{\Delta}\left(Z, \mu_{11}(Z)\right) \\
E_{12}=B & \text { (big) } & \underline{\Xi}\left(Z, \mu_{12}(Z)\right) \\
E_{13}=M & \text { (mean) } & \underline{\Xi}\left(Z, \mu_{13}(Z)\right) \\
E_{14}=S & \text { (small) } & \underline{\Delta}\left(Z, \mu_{14}(Z)\right) \\
E_{15}=N & \text { (natural) } & \underline{\Delta}\left(Z, \mu_{15}(Z)\right)
\end{array}
$$

For $500 \mathrm{kV}$ transmission line in the natural mode, the wave resistance of $287 \mathrm{Ohms}\left(P_{n a t}=870 \mathrm{MVt}\right)[1,5,6]$ is accepted, and the values of the linguistic variables $Z$ "Load resistance" are taken in the interval of $Z=(287 \div \infty) O m$. The generated random values of variable $Z$ correspond to the power limit of $P=(870 \div 0) M V t$.

- The second input parameter for the FLC is "Dynamics" of the fuzzy linguistic variable, where $T_{j}(d Z / d t) \quad$ is term-subset, where $(d Z / d t)_{j} \in E_{2 j}$ and $j=\overline{1,5}$.

$$
\begin{aligned}
& E_{21}=V B \quad(\text { very big }) \quad \triangleq\left(d Z / d t, \mu_{21}(d Z / d t)\right) \\
& E_{22}=B \quad(\mathrm{big}) \quad \underline{\underline{\Delta}}\left(d Z / d t, \mu_{22}(d Z / d t)\right) \\
& E_{23}=Z R \quad \text { (zero) } \quad \triangleq\left(d Z / d t, \mu_{23}(d Z / d t)\right) \\
& E_{24}=S \quad(\text { small }) \quad \triangleq\left(d Z / d t, \mu_{24}(d Z / d t)\right) \\
& E_{25}=V S \quad(\text { very small }) \quad \Delta\left(d Z / d t, \mu_{25}(d Z / d t)\right)
\end{aligned}
$$

Values $T_{j}(d Z / d t)$ of term-subset are accepted in the interval $(-10 \div+10)$.
- The third input parameter for the FLC is "Voltages" of the fuzzy linguistic variable, where $T_{k}(U)$ is term-subset, where $(U)_{k} \in E_{3 k}$ and $k=\overline{1,5}$.

$$
\begin{array}{ccl}
E_{31}=V B & \text { (very big) } & \underline{\Delta}\left(U, \mu_{31}(U)\right) \\
E_{32}=B & \text { (big) } & \underline{\Delta}\left(U, \mu_{32}(U)\right) \\
E_{33}=M & \text { (normal) } & \underline{\Delta}\left(U, \mu_{33}(U)\right) \\
E_{34}=S & \text { (small) } & \underline{\Delta}\left(U, \mu_{34}(U)\right) \\
E_{35}=N & \text { (very big) } & \underline{\Delta}\left(U, \mu_{35}(U)\right)
\end{array}
$$

- The first output parameter of the FLC is "Reactive power" for the fuzzy linguistic variable, $T_{l}\left(Q_{r}\right)$ - term-subset, $Q_{r l} \in E_{4 l}$ and $l=\overline{1,5}$ :

- The second output parameter of the FLC is "Delay time" for the fuzzy linguistic variable, $T_{\gamma}(t)$ term-subset, $t_{\gamma} \in E_{5 \gamma}$ and $\gamma=\overline{1,5}$ :

$$
\begin{aligned}
& E_{51}=V S T \quad \text { (very short) } \Delta\left(t, \mu_{51}(t)\right) \\
& E_{52}=S T \quad \text { (short) } \Delta\left(t, \mu_{52}(t)\right) \\
& E_{53}=M T \quad \text { (mean) } \triangleq\left(t, \mu_{53}(t)\right) \\
& E_{54}=L T \quad \text { (long) } \quad \Delta\left(t, \mu_{54}(t)\right) \\
& E_{55}=V L T \quad \text { (very long) } \triangleq\left(t, \mu_{55}(t)\right)
\end{aligned}
$$

The values of the linguistic variable "Reactive power" are accepted in the interval $P=(870 \div 0) M W \quad(7)$

In the relationships (7)-(11) the $\mu_{1 i}(Z), \quad \mu_{2 j}(d Z / d t), \quad \mu_{3 k}(U), \quad \mu_{4 l}\left(Q_{r}\right), \quad \mu_{5 \gamma}(t)-$ are the membership functions of term-sets of linguistic variables $Z, d Z / d t, U, Q_{r}$ and $t$. These variables are respectively defined in the universal set $E_{1 i}, E_{2 j}, E_{3 k}, E_{4 l}, E_{5 \gamma}$.

The FLC brings into action the reactor power control devices $\left(Q_{r 1}, Q_{r 2}\right)$ depending on the input signals $Z, d Z / d t, U$ and implement 125 fuzzy rules of type (3) based on the Mamdani algorithm.

The definition area of input and output linguistic variables, values of parameters of membership function of separate terms are given in the Table 1. 
Table 1. Terms of linguistic variables, membership functions and their parameters.

\begin{tabular}{|c|c|c|}
\hline $\begin{array}{l}\text { Term- } \\
\text { subsets }\end{array}$ & $\begin{array}{l}\text { Membershi } \\
\text { p functions }\end{array}$ & Parameters \\
\hline \multicolumn{3}{|c|}{ Load resistance, $Z$} \\
\hline Very big & \multirow{5}{*}{ gaussmf } & {$[36,24287]$} \\
\hline Big & & {$\left[\begin{array}{llll}29,38 & 383]\end{array}\right.$} \\
\hline Mean & & {$[50,22 \quad 575]$} \\
\hline Small & & {$\left[\begin{array}{llll}182,75 & 1150\end{array}\right.$} \\
\hline Natural & & {$[425,862300]$} \\
\hline \multicolumn{3}{|c|}{ Load resistance change rate, $d Z / d t$} \\
\hline Very big & \multirow{5}{*}{ gaussmf } & {$\left[\begin{array}{ll}2,1 & 10\end{array}\right]$} \\
\hline Big & & {$[2,15]$} \\
\hline Normal & & {$[2,10]$} \\
\hline Small & & {$[2,1-5]$} \\
\hline $\begin{array}{l}\text { Very } \\
\text { small }\end{array}$ & & {$[2,1-10]$} \\
\hline \multicolumn{3}{|c|}{ Voltage } \\
\hline Very big & \multirow{5}{*}{ gaussmf } & {$[3,2-15]$} \\
\hline Big & & {$[3,2-7,5]$} \\
\hline Normal & & {$[3,20]$} \\
\hline Small & & {$[3,2$ 7,5] } \\
\hline $\begin{array}{l}\text { Very } \\
\text { small }\end{array}$ & & {$[3,2$ 15] } \\
\hline \multicolumn{3}{|c|}{ Reactive power } \\
\hline $\begin{array}{c}\text { Maximu } \\
\mathrm{m}\end{array}$ & \multirow{5}{*}{ gaussmf } & {$\left[\begin{array}{ll}7,33 & 274\end{array}\right]$} \\
\hline Big & & {$\left[\begin{array}{ll}10,54 & 257]\end{array}\right.$} \\
\hline Mean & & {$\left[\begin{array}{ll}21,66 & 206\end{array}\right]$} \\
\hline Small & & {$[33,27$ 120] } \\
\hline Zero & & {$[42,030]$} \\
\hline \multicolumn{3}{|c|}{ Delay } \\
\hline $\begin{array}{l}\text { Very } \\
\text { short }\end{array}$ & $\mathrm{zmf}$ & {$\left[\begin{array}{ll}0 & 0,5\end{array}\right]$} \\
\hline Short & trapmf & {$\left[\begin{array}{llll}0 & 0,05 & 0,15 & 0,2\end{array}\right]$} \\
\hline Mean & trapmf & {$\left[\begin{array}{llll}0.15 & 0,2 & 0,4 & 0.45\end{array}\right]$} \\
\hline Long & trapmf & $\left.\begin{array}{llll}0.4 & 0,45 & 0,85 & 0.95\end{array}\right]$ \\
\hline $\begin{array}{l}\text { Very } \\
\text { long }\end{array}$ & smf & {$\left[\begin{array}{llll}0,8 & 0,9 & 1 & 1\end{array}\right]$} \\
\hline
\end{tabular}

The control matrix-algorithm of reactor power in the format of fuzzy linguistic model "If-then" on the basis of linguistic models (7) - (11) is given in the Table 2. Fuzzy control matrix algorithm consists of 125 rules. The antecedent part of each rule represents three, and the consequent part - two implications.

For defuzzification, i.e. for transition from the phase of fuzzy control actions to a crisp control action, the centroid method [8] is used.
Table 2. Algorithm-matrix of SR fuzzy control

\begin{tabular}{|c|c|c|c|c|c|}
\hline \multirow{2}{*}{ Options } & \multicolumn{2}{|c|}{ Input parameters } & \multicolumn{2}{c|}{$\begin{array}{c}\text { Output } \\
\text { parameters }\end{array}$} \\
\cline { 2 - 6 } & $Z$ & $d Z / d t$ & $U$ & $Q_{r}$ & $L$ \\
\hline 1 & $\mathrm{~N}$ & $\mathrm{VS}$ & $\mathrm{VS}$ & $\mathrm{ZR}$ & $\mathrm{VLT}$ \\
\hline 2 & $\mathrm{~N}$ & $\mathrm{~S}$ & $\mathrm{VS}$ & $\mathrm{ZR}$ & $\mathrm{MT}$ \\
\hline 3 & $\mathrm{~N}$ & $\mathrm{ZR}$ & $\mathrm{VS}$ & $\mathrm{ZR}$ & $\mathrm{ST}$ \\
\hline. &. &. &. &. & $\cdot$ \\
\hline. &. &. &. &. &. \\
\hline 60 & $\mathrm{~S}$ & $\mathrm{VB}$ & $\mathrm{S}$ & $\mathrm{S}$ & $\mathrm{LT}$ \\
\hline 61 & $\mathrm{M}$ & $\mathrm{VS}$ & $\mathrm{S}$ & $\mathrm{ZR}$ & $\mathrm{ST}$ \\
\hline 62 & $\mathrm{M}$ & $\mathrm{S}$ & $\mathrm{S}$ & $\mathrm{S}$ & $\mathrm{ST}$ \\
\hline. &. &. &. &. &. \\
\hline. &. &. &. &. &. \\
\hline 123 & $\mathrm{VB}$ & $\mathrm{ZR}$ & $\mathrm{B}$ & Max & VST \\
\hline 124 & $\mathrm{VB}$ & $\mathrm{B}$ & $\mathrm{B}$ & Max & VST \\
\hline 125 & $\mathrm{VB}$ & $\mathrm{VB}$ & $\mathrm{B}$ & Max & VST \\
\hline
\end{tabular}

\section{Simulation results}

Calculations, simulating the operation of OS-100/500 U1 type shunt reactors with a capacity of 280 MVA, connected at the ends of power lines with a voltage of $500 \mathrm{kV}$ and length of $L=300 \mathrm{~km}$, are made during the simulation.

The surfaces $Q_{r}=\tilde{f}(U, d Z / d t), Q_{r}=\tilde{f}(Z, U)$, $L=\widetilde{f}(U, d Z / d t)$ and $L=\widetilde{f}(Z, U)$ obtained by using the Fuzzy Logic Toolbox module in the Matlab environment, reflecting the relationships "output parameters of the controller - input ones", which show the controller action when controlling the power consumption of the SR, are shown on the Fig. 2. As can be seen from the surface relationships, at $Z=Z_{d}$ $\left(P=P_{n a t}\right) Q_{r} \Rightarrow \min$ and at $Z=\infty \quad(P=0)$ $Q_{r} \Rightarrow \max$, and at intermediate load values with fuzzy control of the SR power, the $Q_{r}$ value is in the range of $Q_{r}=0 \div \max$.

The SR fuzzy control algorithm has been tested for $500 / 330 \mathrm{kV}$ intersystem power grid connecting power systems of Azerbaijan and Georgia, the fragment of the electric circuit is shown on Fig.3.

On the basis of simulation modeling of the proposed fuzzy algorithm for SR control, the calculated experiments for different load modes of the electrical network are carried out. The obtained results for the voltage at the Samukh node of $500 \mathrm{kV}$ SamukhGardabani PTL are shown on the Fig.4. As can be seen from the figure, at the fuzzy SR control depending on the overcurrent along the lines, the voltage on the $500 \mathrm{kV}$ buses is within the prescribed norm.

The curves of the change of power losses during the control depending on the transmitted power in the line and the CSR power are shown on the Fig.5. As can be seen from the figures, at the fuzzy control of the reactive power flow, the active power losses in the considered 
network are reduced in the range from 0.26 to 0.178 , i.e. to $31.5 \%$.

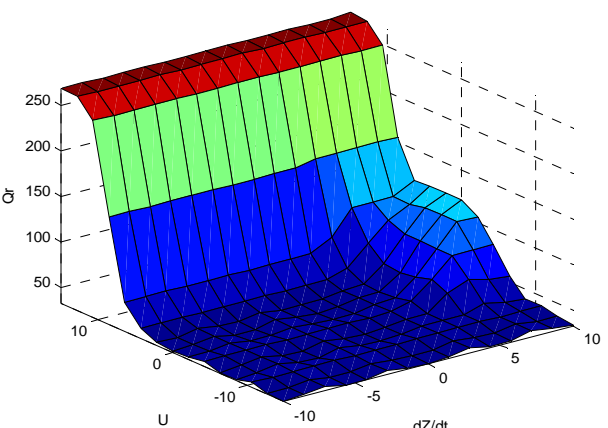

a)

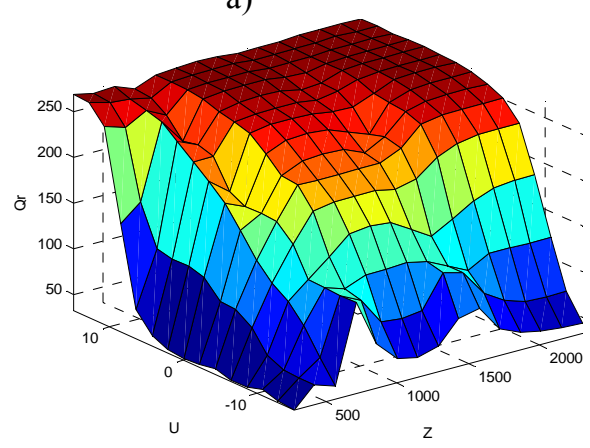

b)

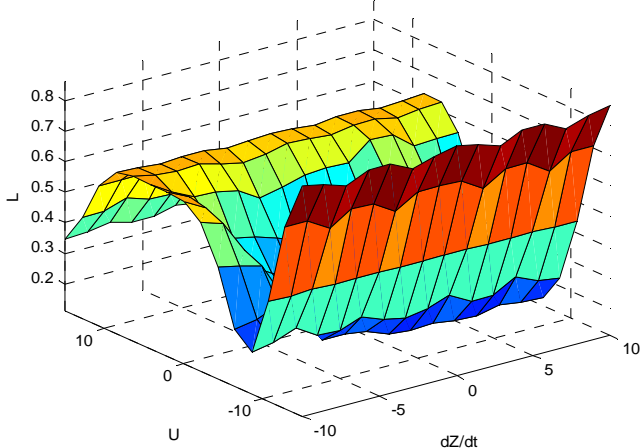

c)

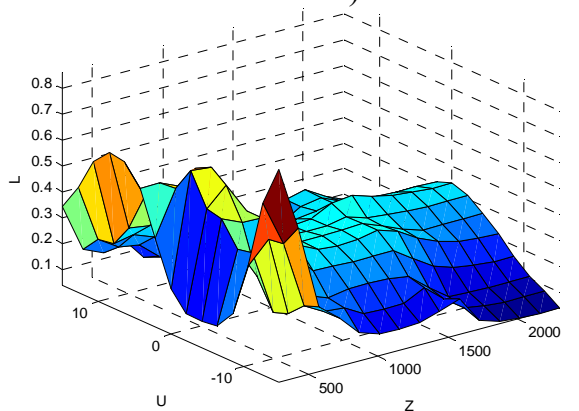

d)

Fig.2. Control surfaces $a-Q_{r}=\tilde{f}(U, d Z / d t)$;

$b-Q_{r}=\tilde{f}(U, Z) ; c-L=\tilde{f}(U, d Z / d t) ; \quad d-L=\tilde{f}(U, Z)$

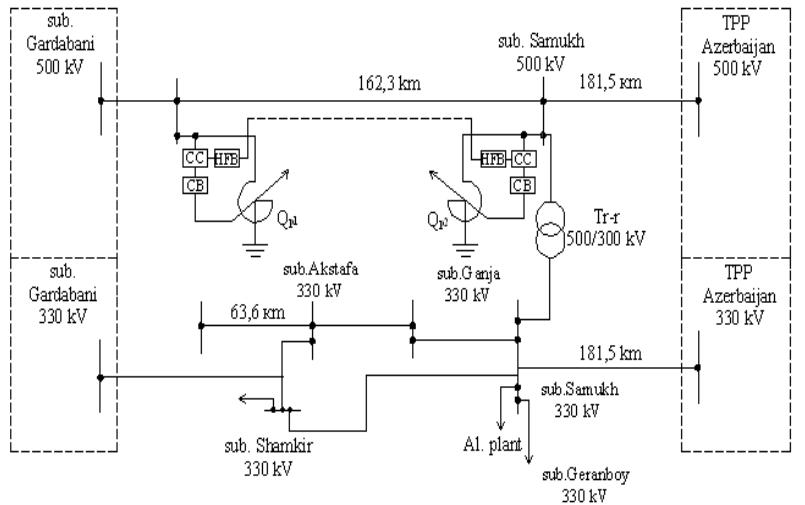

Fig.3. Fragment of the electrical circuit of 500/330 kV network of JSC “Azerenerji” JSC's system

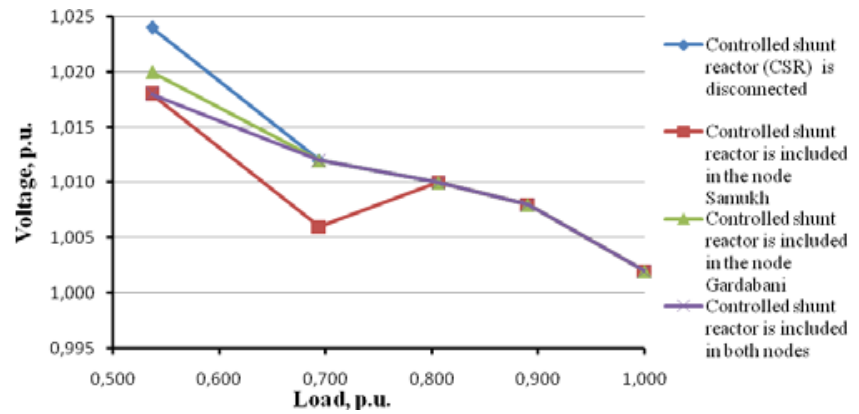

Fig.4. Curves of change of voltage for $500 \mathrm{kV}$ Samukh - Gardabani PTL

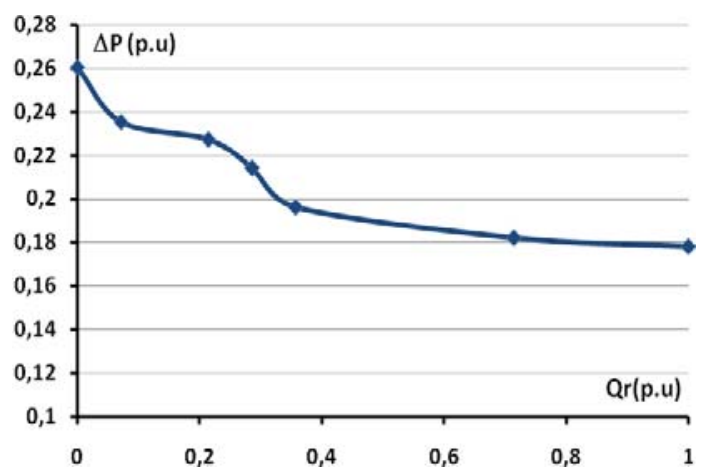

a)

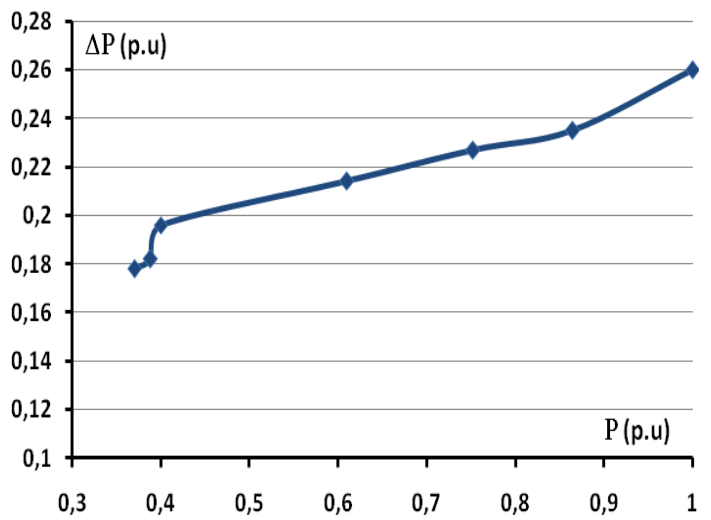

b)

Fig.5. Change in power losses depending on the power of CSR (a) and the power flow (b) 


\section{Conclusion}

1. It is proposed a simple and easily implemented algorithm for the control of power of shunt reactors installed at the ends of power line of the high-voltage power grid on the basis of fuzzy sets and fuzzy logic depending on the values of load and voltage resistance, for damping the voltage fluctuations on the buses of the high-voltage power grid.

2. The results of simulation modeling for the intersystem real electric network of power grids, which implements the proposed control algorithm, confirm its effectiveness. At that, the voltages in the nodes of the high-voltage grid are within the specified permissible limits, and the power losses from the power flow are significantly reduced.

\section{References}

1. V. I. Kochkin, O. P. Nechaev Application of static reactive power compensators in electric networks of power grids and enterprises. M., Publishing house of SC ENAS, 248 (2002)

2. A. Dolgopolov Controlled shunt reactors. M., 112 (2012)

3. P. Bulykin, V.I. Kochkin, L.P. Kubarev, L. L. Fedosov Controlled shunting reactor of new generation. Energoekspert, №3, 46-51 (2011)

4. A.V. Romodin, D. Yu. Leyzgold Approach to the development of models of elements of flexible power lines on the basis of volt-ampere characteristics. Fundamental research, №8, 137-142 (2015)

5. A.M. Hashimov, H.B. Guliyev, A.R. Babayeva IJTPE Journal International Journal on Technical and physical problems of engineering, Issue 30, Vol. 9, No. 1, 18-22 (2017)

6. L.A. Zadeh Fuzzy Sets. Inform. and control, vol. 8, 338-353 (1965)

7. E.S. Pirverdiyev, A. M. Hashimov, H.B. Guliyev, A. R. Babayeva Development of models of fuzzy logic for the control of shunt reactors. Methodical questions of research of reliability of large power systems. Collection of scientific papers. Issue. 68. Research and provision for the reliability of energy systems. Bishkek, 242-251 (2017)

8. A.V. Leonkov Fuzzy modeling in MATLAB and fuzzyTECH environment. BHV Petersburg, St. Petersburg, 736 (2003) 